University of Wollongong

Research Online

Faculty of Social Sciences - Papers (Archive) Faculty of Arts, Social Sciences \& Humanities

2012

Voices in the playground: A qualitative exploration of the barriers and facilitators of lunchtime play

Rebecca M. Stanley

University of Wollongong, rstanley@uow.edu.au

Kobie Boshoff

University of South Australia

James Dollman

University of South Australia

Follow this and additional works at: https://ro.uow.edu.au/sspapers

Part of the Education Commons, and the Social and Behavioral Sciences Commons

Research Online is the open access institutional repository for the University of Wollongong. For further information contact the UOW Library: research-pubs@uow.edu.au 


\title{
Voices in the playground: A qualitative exploration of the barriers and facilitators of lunchtime play
}

\begin{abstract}
Objectives: To explore children's perceptions of the factors influencing their engagement in physical activity during the "critical" lunchtime period, using a social-ecological framework. Design: This study was an in-depth descriptive qualitative design. Methods: Fifty-four South Australian children aged 10-13 years participated in same-gender focus groups. Transcripts, field notes and activity documents were analysed using content analysis. Using an inductive thematic approach, data were coded and categorised into perceived barriers and facilitators according to a social-ecological model. Results: Children identified a range of environmental, social and intrapersonal barriers and facilitators. Bullying/teasing, the school uniform and school rules were exposed as explicit barriers to lunchtime play. Other important barriers included lack of access to, and poor suitability of, space, lack of access to programs/facilities and equipment, and lack of peer and teacher support. Perceived facilitators of lunchtime physical activity centred on access to equipment, enjoyment, motivation to improve skills, and peer support and acceptance. The freedom to make up or modify rules for games was also perceived to be a facilitator of lunchtime play. Conclusions: Communicating with children has been an effective approach in uncovering perceived barriers and facilitators to lunchtime play that may not have been previously considered in the quantitative correlate literature. Lunchtime interventions targeting children's physical activity should focus on addressing the barriers perceived to be important to lunchtime play.
\end{abstract}

\section{Keywords}

lunchtime, play, playground, qualitative, exploration, voices, barriers, facilitators

\section{Disciplines}

Education | Social and Behavioral Sciences

\section{Publication Details}

Stanley, R. M., Boshoff, K. \& Dollman, J. (2012). Voices in the playground: A qualitative exploration of the barriers and facilitators of lunchtime play. Journal of Science and Medicine in Sport, 15 (1), 44-51. 
2 Voices in the playground: A qualitative exploration of the barriers and facilitators

$5 \quad{ }^{a}$ Health and Use of Time Group, School of Health Sciences, University of South Australia, GPO Box 2471, Adelaide, 5001, Australia.

$7 \quad{ }^{b}$ School of Health Sciences, University of South Australia, GPO Box 2471, Adelaide, 5001, Australia.

8

$9 *$ Corresponding author.

10 E-mail address: starm002@mymail.unisa.edu.au (Rebecca M Stanley). 


\section{Abstract}

12 Objectives: To explore children's perceptions of the factors influencing their engagement in physical

13 activity during the "critical” lunchtime period, using a social-ecological framework.

14 Design: This study was an in-depth descriptive qualitative design.

15 Methods: Fifty-four South Australian children aged 10 to 13 years participated in same-gender focus 16 groups. Transcripts, field notes and activity documents were analysed using content analysis. Using an

17 inductive thematic approach, data were coded and categorised into perceived barriers and facilitators

18 according to a social-ecological model.

19 Results: Children identified a range of environmental, social and intrapersonal barriers and facilitators.

20 Bullying/teasing, the school uniform and school rules were exposed as explicit barriers to lunchtime play.

21 Other important barriers included lack of access to, and poor suitability of, space, lack of access to

22 programs/facilities and equipment, and lack of peer and teacher support. Perceived facilitators of

23 lunchtime physical activity centred on access to equipment, enjoyment, motivation to improve skills, and

24 peer support and acceptance. The freedom to make up or modify rules for games was also perceived to be 25 a facilitator of lunchtime play.

26 Conclusions: Communicating with children has been an effective approach in uncovering perceived

27 barriers and facilitators to lunchtime play that may not have been previously considered in the

28 quantitative correlate literature. Lunchtime interventions targeting children's physical activity should

29 focus on addressing the barriers perceived to be important to lunchtime play.

30 Keywords: Physical activity; Focus groups; Children; Leisure activities; Facilitators; Barriers. 


\section{Introduction}

According to the Australian National Guidelines, children are encouraged to obtain at least 60 minutes of moderate-to-vigorous physical activity (PA) a day and no more than two hours of electronic media per day ${ }^{1}$. Given that children spend a large proportion of their day at school, this setting has been identified as ideal for PA promotion with multiple opportunities to contribute to their recommended daily activity “dose” without interfering with academic schedules ${ }^{2}$. With concerns that allocated physical education is not meeting statutory requirements ${ }^{3}$, the lunchtime period has been identified as a "critical window” for PA promotion within a school day ${ }^{4}$.

The lunchtime period, or also referred to as "recess", is a regularly scheduled time where all children within a school are generally given equal opportunity for unstructured PA, regardless of gender, ethnicity and socioeconomic background ${ }^{2}$. Research has shown that children can obtain up to 33\% of their recommended daily moderate-to-vigorous PA during this period ${ }^{4}$. In a study using pedometers, the lunchtime period was identified as the most important component of a school day, contributing up to $16 \%$ of daily PA ${ }^{5}$. However, there is evidence that many children are not taking advantage of this period for PA. Ridgers et al. ${ }^{6}$ found that boys and girls spent only $32.9 \%$ and $23 \%$ of their total lunchtime in moderate-to-vigorous PA, respectively. Hence, further research is required to understand influences on PA during this "critical window”.

Little research has been conducted into the factors influencing lunchtime play. Current research has predominantly been quantitative, with a significant focus on cross-sectional surveys ${ }^{7}$ and schoolbased intervention studies ${ }^{4}$. Quantitative surveys tend to assess the relationship between factors and "global” PA, or focus on a narrow set of predefined factors, which are often inferred by adults ${ }^{8}$ and may have limited relevance to the specific setting or behaviour under investigation. A social-ecological model posits that PA behaviour results from multiple influences, including intrapersonal, social and physical environmental factors ${ }^{9,10}$. However, no studies to date have explicitly and comprehensively explored these multi-faceted influences of lunchtime PA from a qualitative perspective. 
57 This study was the first phase of a larger study in which the overall purpose was to develop a physical

58 activity correlate questionnaire that could be administered in school settings. To address current

59 recommendations to explore the influences on specific PA behaviour in specific contexts ${ }^{4}$, the aim of this

60 study to explore children's perceptions of the factors influencing their engagement in PA during the

61 lunchtime period, using a descriptive qualitative approach ${ }^{11}$. The findings from this study will be used to

62 inform the questionnaire content in the larger study.

63

64 2. Methods

Maximum variation purposive sampling was used to select boys and girls across a range of

66 socioeconomic status (SES), geographic location and school types, in order to obtain a diverse description

67 of potential influences on children's lunchtime PA ${ }^{12}$. A list of all South Australian government and non-

68 government schools was obtained along with their School Card Register (SCR). The SCR is the

69 percentage of students in a school whose families receive government support to meet the costs of school

70 attendance and is therefore an indicator of SES at the school level. The list of schools was stratified

71 according to the SCR score and split at the $50^{\text {th }}$ percentile to categorise high and low SES schools. Six

72 schools were purposively selected from the stratified school list to reflect the range of school types,

73 socioeconomic status (SES) and geographic locations in South Australia and included a rural school, a

74 non-government single-sex female school, a non-government single-sex male school, a non-government

75 co-educational school, a high SES government co-educational school and a low SES governmental co-

76 educational school. The Principal or nominated teacher was asked to identify nine potential participants

77 from each gender across Years 5, 6 and 7 who were: aged between 10 and 13 years; spoke and understood

78 English; did not have a diagnosed physical, intellectual or sensory disability; represented diversity in

79 activity level (i.e. active or not very active); and were comfortable talking in group situations. A total of

8054 participants (23 males), with a mean age of $11.05( \pm 0.86)$ years, provided informed parental/legal 
81 guardian consent to participate in the focus groups. Of these participants, $20 \%$ attended a low SES school 82 (SCR cut-off for low SES $=31.8 \% ; 50^{\text {th }}$ percentile).

84 Committee, Department of Education and Children Services (DECS), the South Australian Commission 85 for Catholic Schools (SACCS) and from the relevant school authorities. In-depth semi-structured focus groups were chosen to explore children’s perceptions of factors

87 influencing their engagement in lunchtime $\mathrm{PA}^{13}$. Using the social-ecological model as a guide ${ }^{9,10}$, a

88 number of prompting questions were developed to obtain information about intrapersonal, social and

89 physical environmental influences, as outlined in Table 1. The questioning route was reviewed for

90 structure, content and expected length by a panel of experts with research experience in conducting

91 children's focus groups. Modifications to the number of questions per focus group were made based on

92 the experts’ previous experience with similar participant groups. In addition, discussion-stimulating

93 activities were included into the focus group questioning route, which were recommended by the panel of

94 experts and the literature ${ }^{14}$. The questioning route was piloted with a group of children from Year 5, 6

95 and 7 in a South Australian school to ensure that the questions could be answered within an appropriate

96 timeframe, were worded and sequenced appropriately and elicited the required information ${ }^{15,16}$.

$97 \quad * * * *$ Insert Table 1 about here ${ }^{* * * *}$

98 Eleven focus groups were conducted on school premises during class time across winter months

99 (April to early July). Focus groups ran for approximately one hour and the size of the groups ranged from

100 two to nine participants, with only two of the eleven groups containing less than four participants.

101 Separate male and female focus groups were conducted to provide a safe environment to discuss gender-

102 specific factors, such as body image ${ }^{16}$. The first author facilitated the groups, supported by a trained

103 research assistant. The discussions were audio-taped and transcribed verbatim ${ }^{15}$.

Each focus group followed the same basic structure, described in Table 1. To focus thinking

105 around the concept of physical activity ${ }^{8}$, children were asked the question, "What is the first 
thing that comes to mind when you hear the word physical activity?” Following responses from the children, the facilitator provided a definition and asked the children to come up with terms that they would like to use in the discussion. "Play" and "Sport" were the most common terms used. Following this introduction, children were asked to take the facilitators on a tour of the school, by pointing out where they play at lunchtime and the activity they played, using a bird's eye map of the school printed from "Google Earth” (2009 Google). A picture of a stick figure and a drawing of the activity were placed on the map to indicate where and what they played in the school yard. This approach has been successfully used in other studies relating to children's perceptions of their environment ${ }^{8,17}$. The map was used to stimulate discussion topics and was regularly referred to during the discussion.

Factors mentioned were documented on a whiteboard until saturation was reached (i.e. when no new ideas were expressed) ${ }^{15}$. To ensure rigour of the data, member checking occurred, during which children were given an opportunity to make any changes or additions to the list before the conclusion of the session. Children were given time at the end of the discussion to identify what they thought were the five most important factors. Each child was given five sticker dots and was asked to approach the whiteboard as a group and place the stickers next to the corresponding factors.

The audio-tapes were transcribed verbatim immediately following the discussion to increase trustworthiness of the data. The transcripts and whiteboard summaries were used in the analysis. Qualitative content analysis using a long table inductive thematic approach ${ }^{11,15}$ was used to analyse the data. Comments were coded and arranged on poster boards under headings derived from the socialecological model (intrapersonal, social environment and physical environment characteristics), which was used to provide a context for interpreting and summarizing the range of factors identified by the children. Under each heading the coded comments were "clustered” into major categories and sub-categories based on similar content. Analysis was conducted separately by the first author and an external coder. Coding and clustering discrepancies were discussed with the research team until 100\% agreement was reached. 
131 The list of factors and sticker dot frequencies were then used to guide the development of a set of

132 prioritised factors, according to children's perceived importance ${ }^{11}$, which were triangulated with the

133 whiteboard summaries of the factors identified during the focus groups.

\section{Results}

Perceived facilitators and barriers congregated under three major headings corresponding to intrapersonal, physical environment and social characteristics. A total of 64 factors were identified by the children with varying degrees of perceived importance. Due to the vast array of factors identified by the children, only the factors perceived as the most important by the children and/or were unique to the

140 lunchtime setting will be described here. Perceived importance was interpreted from the sticker dot activity, the number of verbalisations and the enthusiasm with which factors were described. Factors perceived as the most important contained more than five sticker dots, ten or more related comments

143 and/or discussed with a lot of enthusiasm by the participants. Enthusiasm was interpreted from 144 observations during the focus groups by the principal researcher and the research assistant and was based 145 on observations of non-verbal responses, vocal intonation and eagerness to discuss a topic.

As outlined in Table 2, participants identified a number of barriers across all components of the 147 social-ecological model. Most of the physical environmental factors were perceived to be barriers to 148 lunchtime play. "Lack of access to space" was defined as space being available but not accessible. A 149 number of reasons for inaccessibility included peers taking up the space for sedentary activities (sitting 150 and talking); space being used for other school-related activities (e.g. training); and the condition of a 151 space. Another aspect of accessibility was the suitability of a space for a particular activity. For instance, 152 there may be times when available play spaces are not conducive to a particular activity. "Lack of access 153 to programs/facilities” was a common barrier across most schools. "Lack of facilities” was linked to 154 safety concerns and cost of facilities. “Access to equipment” was consistently raised in all schools, with 155 emphasis on current poor condition and maintenance of equipment, rather than lack of equipment. 
Another consistently mentioned factor across most schools was “weather”. In extreme weather,

157 such as very hot or very wet conditions, opportunities to be active were restricted by the school's weather

158 policy. "Uniform” was a factor discussed only briefly by girls but had a pertinent affiliation to the

159 lunchtime setting, particularly in high SES schools. When girls were asked why they chose certain

160 activities over others, uniforms was identified as a significant restriction to playing specific types of

161 activities, such as basketball. Children identified "other commitments”, such as meetings, music practice,

162 and sport shed duty, as important barriers. "School rules" were not only raised in relation to specific

163 factors, such as space and weather, but also enthusiastically discussed in general. These rules often had a

164 negative connotation and were seen as a major barrier to lunchtime play.

165 Perceived competence, lack of motivation and preference for sedentary pursuits were all

166 perceived as intrapersonal barriers to lunchtime play among boys and girls. These factors often led to

167 children believing that an activity was not worth pursuing.

Social barriers in the school yard fell into two major categories: "Peer influence” and "Teacher

influence”. An unexpected peer influence to play identified by the majority of children was

"bullying/teasing”. A direct influence of bullying was the prevention of children playing in certain areas

171 of the school yard or with pieces of equipment. Avoidance behaviour as a result of being bullied also

172 appeared to have an indirect influence on lunchtime play. Teachers were identified as another social

173 influence on lunchtime play. With a requirement to enforce school policies and maintain children's safety,

174 teachers are sometimes perceived as "the bad people”, preventing children from playing certain games at

175 lunchtime.

176

177

****Insert Table 2 about here ${ }^{* * * *}$

Table 3 outlines the facilitators perceived to be important during the lunchtime period. Depending on the context in which factors were described, some of these, such as suitability of space, were also

181 identified as barriers to PA. However, in this context the availability of a space suitable for a specific 
182

183

184

185

186

187

188

189

190

191

192

193

194

195

196

197

198

199

200

201

202

203

204

205

206

207

activity assisted children to play at lunchtime. For example, if children want to play football, they would choose to play on the oval instead of the tennis courts. Similarly, accessibility of equipment was consistently broached as an important facilitator and barrier across all schools. Most of the schools provide opportunities for children to use equipment by giving them access to the sports shed, which was perceived as an important facilitator of play. The type of weather was identified as a motivating factor for children, in that they would select a specific activity based on the weather.

A number of intrapersonal factors were identified as facilitators of lunchtime play. When children were asked why they participated in activities, the most common, and often the first response across all groups was “because it’s fun" or "I enjoy it". When asked to explain this response in more detail, participants gave specific examples of what makes activities fun. For example, boys found an activity fun because “it’s dangerous”, while girls described fun in relation to activities being challenging. Lunchtime play was also considered fun if it meant hanging out with friends.

Behavioural attitudes, beliefs and feelings about lunchtime play were also perceived to be facilitators. When asked “why do kids play sports/games at lunchtime”, responses centred on improving skills or getting practice. Hanging out with friends was another factor that motivated lunchtime play. All comments relating to beliefs about PA were considered facilitators. For example, children chose to play at lunchtime because it gave them "something to do". A unique characteristic of free play at lunchtime was children's freedom to “make up their own rules”. This assisted in making lunchtime games more fun and facilitated motivation to play games. Of particular note, children commented that they often modify existing rules to match personal and group capabilities, making lunchtime play more appealing.

In the “peer influence” category, “someone/friends to play with” was one of the most important factors facilitating play. Children believed that having friends or someone to hang out with created opportunities for play, contributed to the enjoyment of the activity and made activities worthwhile. "Peer acceptance” was another important factor. “Teacher Influence”, in particular teacher support, was only mentioned by children from two of the schools and was not considered as important as peer influence. Irrespective of this, children commented that teachers sometimes helped with their play at lunchtime. 


\section{Discussion}

The literature has emphasised a need for explicit description of PA-related factors that are pertinent to specific settings from the perceptive of children ${ }^{18}$. This in turn will give meaning to existing

214 evidence and direct future PA promotion efforts. This study has contributed to the current literature by 215 specifically examining children's perceptions of the factors that facilitate and hinder their PA during the 216 critical school lunchtime period.

A number of barriers and facilitators identified in this in-depth descriptive qualitative study concur with existing quantitative evidence of factors influencing “global” PA. These factors include access to and suitability of space ${ }^{19}$, access to programs/facilities and equipment ${ }^{20}$, enjoyment ${ }^{7}$, peer support ${ }^{7}$, teacher support ${ }^{7}$ and perceived competence ${ }^{7}$. This study has contributed to existing evidence by exploring these factors in the context of the lunchtime school setting and exposing a number of factors unique to lunchtime play, which have not previously been investigated in detail in the quantitative socialecological correlate literature or included in PA correlate questionnaires. These factors include the school uniform, bullying/teasing, school rules and the value of making up rules for games.

229 the private school sector, restricts movement and is generally impractical for the majority of physical 230 activities. This leads to feelings of discomfort, particularly in mixed-gender environments, and reluctance 231 to engage in play. A qualitative study ${ }^{22}$ found that girls felt uncomfortable wearing the required sex232 specific physical education uniform of short skirts during physical education classes, preferring to not 233 participate in mixed-gender activities. In addition, the students also felt the skirt uniform was 
234 inappropriate for the activities chosen during physical education class, preferring uni-sex uniforms 235 consisting of shorts, t-shirts and jumpers. In private schools, children are often not allowed to wear their 236 physical education uniform outside of physical education lessons. Schools could potentially reconsider 237 policies to allow a uni-sex physical education uniform during the lunchtime period. A practical design 238 allowing ease of movement would increase children's feelings of comfort and self-confidence when 239 engaging in physical activities.

240 Bullying/teasing in the school yard is not a new phenomenon and is well documented in the 241 literature, as evidenced by systematic reviews ${ }^{23,24}$. However, this factor has only recently emerged in the 242 PA correlate literature as an important barrier to PA. Casey and colleagues ${ }^{25}$ found that teasing was 243 linked with skill competence in activities, with the indirect outcome of reduced confidence and avoidance 244 of PA. Bauer and colleagues ${ }^{26}$ also reported that children experienced direct gender and weight-related 245 bullying, inhibiting full engagement in PA. The participants in this current study also discussed examples of direct bullying in which other children would physically stop children from engaging in activities by

247 stealing equipment and chasing them out of play spaces. Bullying/teasing can have profound negative effects on self-confidence and can potentially lead to a preference for sedentary activities in lieu of PA ${ }^{25,26}$. As this is a relatively recent concept in the PA literature, additional research is required to understand the full extent of the influence of bullying/teasing on children's PA. constrained by school rules. Rules tended to cluster around what they were allowed to play, who they

253 played with and where they played. Even though school rules are established for safety and legal reasons 254 and a means of controlling situations ${ }^{7}$, schools need to be aware that children generally perceive these to 255 be barriers to their lunchtime play, in which access to spaces, equipment and ultimately their 256 opportunities to be active, are restricted.

258 play. Lunchtime PA is often characterised by its unstructured nature. According to MacDougall and 259 colleagues ${ }^{27}$, children hold a unique meaning for "play”, which is quite distinguishable from other forms 
260

261

262

263

264

265

266

267

268

269

270

271

272

273 choice, children are more likely to be motivated to engage in $\mathrm{PA}^{30}$. Even though Wilson and colleagues’

$274{ }^{30}$ findings were based on non-specific PA, this current study has confirmed that the concept is applicable

of PA. Play is often linked with fun, spontaneity, interaction with friends, and with no competitive components. Humbert and colleagues ${ }^{18}$ reported that children want to be able to choose the level of competition in any PA context and to make their own rules. In addition, a study by McKenzie and colleagues ${ }^{28}$ found children engaged in less moderate to vigorous physical activity during school break times in areas that were highly structured through supervision or with organised activities compared to unstructured play areas. The opportunity and the freedom to modify activities to be less competitive, to change the physical demands of an activity and to include other children, can enhance opportunities and promote enjoyment and motivation to engage in activities ${ }^{18}$.

Hohepa and colleagues ${ }^{29}$ reported that the barriers and facilitators of PA are predominantly based on perceptions of choice. The majority of the barriers tend to relate to aspects that children perceived to be out of their control. For example, access to equipment was controlled and often restricted by the school, and hence viewed as a barrier. However, when asked what would facilitate PA, participants identified increased access to equipment as an appropriate solution. By increasing opportunities and to the school lunchtime setting and should be considered during the development of PA interventions. When considering these findings, some limitations should be noted. School policies and physical

277 environments tend to vary across Australian states and between schools, thus limiting the generalisability 278 of the results. Only one focus group was run per group of children, restricting opportunities to follow up 279 and explore the identified factors in further detail. Also, some focus groups had a small number of 280 participants in the group, which may have affected the richness of discussion and reduced the ability to 281 expose additional factors. The identification of the five most important factors may have been influenced 282 by instructing the children to complete this activity in front of each other. An alternative approach could 283 have been to ask the children to identify the five most important activities one at a time without the other 284 focus group members in the room. 
286

287

288

289

290

291

292

293

294

295

296

297

298

299

300

301

302

303

304

305

306

307

308

309

310

311

To the authors' knowledge this is the only qualitative study that has looked specifically at the lunchtime period. The findings from this study can be used by schools, health promoters and policy makers to develop appropriately targeted lunchtime PA interventions or modify existing policies in order to increase children's choices and opportunities to be active at lunchtime. Furthermore, researchers using quantitative methodologies could apply these findings to the development of questionnaires that are designed to predict setting-specific PA. The concept of exploring setting-specific PA and related factors could be expanded to examine other settings and times of the day or year, such as the school holidays. Additional research is needed to explore the impact of the relatively new factors, such as the influence of the uniform and bullying, on children’s lunchtime-specific PA behaviour.

\section{Conclusion}

The current literature on the factors influencing PA tend to account for approximately 15 to 20\% of the variance in children's PA ${ }^{18}$. These findings suggest that there is a need to better understand the factors and search for new factors in order to provide a more comprehensive picture of influences on children's PA behaviour ${ }^{18}$. The current study has provided a unique opportunity to explore an array of factors in the context of the lunchtime period and gain a more in-depth understanding of the influences of children’s lunchtime play from the children's perspective. Lunchtime interventions targeting children's PA should focus on addressing the barriers perceived to be important to lunchtime play and modify these to increase children's PA opportunities and choices in lunchtime settings.

\section{Practical Implications}

- Communicating with children provides a unique opportunity to uncover new factors and better understand the factors that influence children's PA in the context of the lunchtime period.

- Efforts to promote PA in school settings should focus on addressing important barriers, such as bullying/teasing and access to space and equipment, to increase children’s PA opportunities and perceptions of choice in the school yard. 
- Questionnaires targeting setting-specific PA among children should be designed to incorporate barriers and facilitators as perceived by children.

\section{Acknowledgements}

Rebecca Stanley acknowledges the support from University of South Australia for providing the resources necessary to complete this study. This work was conducted during a $\mathrm{PhD}$ candidature in which Rebecca is supported by an Australian Postgraduate Award Scholarship and a University of South Australia Top Up Scholarship.

\section{References}

1. Department of Health and Ageing. Australia's physical activity recommendations for 5-12 year olds. Canberra: Commonwealth of Australia;2004.

2. Beighle A, Morgan CF, Le Masurier G, et al. Children's physical activity during recess and outside of school. J Sch Health. 2006;76(10):516-520.

3. McKenzie TL, Marshall SJ, Sallis JF, et al. Student activity levels, lesson context, and teacher behavior during middle school physical education. Res Q Exerc Sport. Sep 2000;71(3):249-259.

4. Ridgers ND, Stratton G, Fairclough SJ. Physical activity levels of children during school playtime. Sports Med. 2006;36(4):359-371.

5. Tudor-Locke C, Lee SM, Morgan CF, et al. Children's pedometer-determined physical activity during the segmented school day. Med Sci Sports Exerc. Oct 2006;38(10):1732-1738.

6. Ridgers ND, Stratton G, Fairclough SJ. Assessing physical activity during recess using accelerometry. Prev Med. Jul 2005;41(1):102-107.

7. Ommundsen Y, Klasson-Heggebo L, Anderssen SA. Psycho-social and environmental correlates of location-specific physical activity among 9- and 15- year-old Norwegian boys and girls: the European Youth Heart Study. Int J Behav Nutr Phys Act. 2006;3:32. 
337 8. Darbyshire P, MacDougall C, Schiller W. Multiple methods in qualitative research with children: more insight or just more? Qual Res. 2005;5(4):417-436.

9. Spence JC, Lee RE. Toward a comprehensive model of physical activity. Psych of Sport Ex. 2003;4:7-24.

10. Sallis J, Owen N, Fisher E. Ecological models of health behaviour. In: Glanz K, Rimer B, Viswanath K, Orleans C, eds. Health behaviour and health education: theory, research, and practice. San Francisco: Jossey-Bass Publishers; 2008:465-485.

11. Sandelowski M. Whatever happened to qualitative description? Res Nursing \& Health. 2000;23(4):334-340.

12. Patton M. Qualitative Research and Evaluation Methods. 3rd ed. Thousand Oaks, California: Sage Publications, Inc; 2002.

13. Kennedy C, Kools S, Krueger R. Methodological Considerations in Children's Focus Groups. Nursing Res. 2001;50(3):184-187.

14. Colucci E. "Focus groups can be fun": the use of activity-oriented questions in focus group discussions. Qual Health Res. Dec 2007;17(10):1422-1433.

15. Krueger R, Casey M. Focus groups: A practical guide for applied research. Thousand Oaks: Sage Publications Ltd; 2000.

16. Peterson-Sweeney K. The use of focus groups in pediatric and adolescent research. J Paediatr Health Care. 2005;19(2):104-110.

17. Veitch J, Salmon J, Ball K. Children's active free play in local neighborhoods: a behavioral mapping study. Health Educ Res. Oct 2008;23(5):870-879.

18. Humbert ML, Chad KE, Bruner MW, et al. Using a naturalistic ecological approach to examine

19. Harten N, Olds T, Dollman J. The effects of gender, motor skills and play area on the free play activities of 8-11 year old school children. Health Place. 2008;14(3):386-393. 
363

20. Haug E, Torsheim T, Sallis JF, et al. The characteristics of the outdoor school environment associated with physical activity. Health Educ. Res. 2008.

21. Meadmore D, Symes C. Keeping up Appearances: Uniform Policy for School Diversity? Bri J Educ Stud. 1997;45(2):174-186.

22. Williams A, Bedward J. Understanding girls' experience of physical education: relational analysis and situated learning. In: Penney D, ed. Gender and Physical Education: Contemporary issues and future directions. London: Routledge 2002.

23. Espelage DL, Swearer SM. Research on School Bullying and Victimization: What Have We Learned and Where Do We Go from Here? School Psych Rev. 2003;32(3):365-383.

24. Merrell K, Gueldner B, Ross S, et al. How effective are school bullying intervention programs? A meta-analysis of intervention research. . School Psych Quart. 2008;23(1):26-42.

25. Casey MM, Eime RM, Payne WR, et al. Using a socioecological approach to examine participation in sport and physical activity among rural adolescent girls. Qual Health Res. 2009;19(7):881-893.

26. Bauer KW, Yang YW, Austin SB. "How can we stay healthy when you're throwing all of this in front of us?" Findings from focus groups and interviews in middle schools on environmental influences on nutrition and physical activity. Health Educ Behav. Feb 2004;31(1):34-46.

27. MacDougall C, Schiller W, Darbyshire P. We have to live in the future. Early Child Dev Care. 2004;174(4):369-387.

28. McKenzie TL, Marshall SJ, Sallis JF, et al. Leisure-time physical activity in school environments: an observational study using SOPLAY. Preventive Medicine. Jan 2000;30(1):7077.

29. Hohepa M, Schofield G, Kolt GS. Physical Activity: What Do High School Students Think? J Adolesc Health. 2006;39(3):328-336. 
387 30. Wilson DK, Williams J, Evans A, et al. Brief report: a qualitative study of gender preferences and motivational factors for physical activity in underserved adolescents. J Pediatr Psychol. Apr-May 2005;30(3):293-297.

390

391 
Table 1

393 Focus group procedure and questions used during discussions

The procedure for each focus group was as follows:

1. Introductory discussion to focus thinking around the concept of physical activity.

2. School yard mapping activity where children identified where they usually played at lunchtime and the activity they played.

3. A discussion to identify factors that influence children's lunchtime play using the following questions.

When thinking about the time you spend during lunchtime at school...can you tell me about...

- What influences your lunchtime physical activity?

- Why do you/others do this activity?

- Is there anyone who helps you do this activity?

- What helps you or stops you from doing this activity?

- Is there anything that you would really like to do at lunchtime that you can't do or don't do?

- Was there ever a time when you stopped being active at lunchtime?

- What do you think stops children from playing elsewhere in the school yard?

- When you and others are doing this activity, is there anything you have to be careful about?

- Who do you do this activity with?

- What do you think schools can do to help children be more active at lunchtime?

4. Sticker dot activity where children identified the five most important factors. 
Table 2

396 The most important perceived barriers to lunchtime physical activity

\begin{tabular}{|c|c|c|}
\hline Factors & Sub-factors & Quotes \\
\hline \multicolumn{3}{|l|}{ Physical Environment } \\
\hline \multirow[t]{5}{*}{ Access to space } & $\begin{array}{l}- \text { Lack of access to } \\
\text { space }\end{array}$ & "Where ever you can play, everyone sits there." \\
\hline & - Size of space & $\begin{array}{l}\text { “...sometimes you don’t have an area that you can play in. } \\
\text { There’s just not enough room in the school.” }\end{array}$ \\
\hline & $\begin{array}{l}\text { - Number of people } \\
\text { in space }\end{array}$ & $\begin{array}{l}\text { "Even though it’s a big school there's lots of people and } \\
\text { almost not enough room.” }\end{array}$ \\
\hline & $\begin{array}{l}\text { - Schools rules } \\
\text { (where you are } \\
\text { allowed to play) }\end{array}$ & $\begin{array}{l}\text { "We're not allowed to play [in certain areas of the } \\
\text { school]." }\end{array}$ \\
\hline & • Condition of space & "The grass gets dry and it hurts when you fall over." \\
\hline Suitability of space & $\begin{array}{l}\text { - Suitability of space } \\
\text { for a chosen } \\
\text { activity }\end{array}$ & $\begin{array}{l}\text { "In the junior school there’s [no hiding spaces], it’s so } \\
\text { open.” }\end{array}$ \\
\hline $\begin{array}{l}\text { Access to } \\
\text { programs/facilities }\end{array}$ & $\begin{array}{l}\text { - Lack of access to } \\
\text { programs/facilities }\end{array}$ & "We don’t have a pool." \\
\hline $\begin{array}{l}\text { Access to } \\
\text { equipment }\end{array}$ & $\begin{array}{l}\text { - Condition of } \\
\text { equipment }\end{array}$ & $\begin{array}{l}\text { "There used to be a soccer net and there used to be footy } \\
\text { goals. But they were destroyed." }\end{array}$ \\
\hline \multirow[t]{2}{*}{ Weather } & - Weather Policy & $\begin{array}{l}\text { "If it is over } 36 \text { [degrees] you have to stay in and if it’s } \\
\text { raining they ring the bell three times and you have to go } \\
\text { in." }\end{array}$ \\
\hline & - Types of weather & $\begin{array}{l}\text { "When it's hot you just kind of sit around and you don’t } \\
\text { want to do anything." }\end{array}$ \\
\hline Uniform & & $\begin{array}{l}\text { "Hats is one big influence...No hat, no play.” } \\
\text { "Uniforms cut you back from running and stuff.” }\end{array}$ \\
\hline Cost & & "Costs too much money [to build facilities].” \\
\hline Safety & - Injury avoidance & $\begin{array}{l}\text { "Lots of older girls walk around at lunch and when you run } \\
\text { passed them you almost knock them down so you have to } \\
\text { walk." }\end{array}$ \\
\hline Time constraints & - Other & “Sometimes you have meetings so you can’t go outside to \\
\hline
\end{tabular}


commitments play.”

School policy

“We are only allowed to run on the grass but we're not allowed to run around the hall, around buildings and if we do we'll get time out.”

\begin{tabular}{|c|c|c|}
\hline \multicolumn{3}{|l|}{ Intrapersonal } \\
\hline Self-efficacy & $\begin{array}{l}\text { - Perceived } \\
\text { competence }\end{array}$ & "I suck at physical running and stuff so I do nothing." \\
\hline $\begin{array}{l}\text { Behavioural } \\
\text { attitude }\end{array}$ & - Lack of motivation & $\begin{array}{l}\text { "There's not much things to do at school really. It's really } \\
\text { boring.” }\end{array}$ \\
\hline $\begin{array}{l}\text { Feelings about } \\
\text { physical activity }\end{array}$ & $\begin{array}{l}\text { - Activity preference } \\
\text { for sedentary } \\
\text { pursuits }\end{array}$ & $\begin{array}{l}\text { "Some people think that [school] subjects are more fun } \\
\text { than actual play time." }\end{array}$ \\
\hline \multicolumn{3}{|c|}{ Social environmental } \\
\hline Peer Influence & $\begin{array}{l}\text { - No-one to play } \\
\text { with } \\
\text { - Bullying/teasing }\end{array}$ & $\begin{array}{l}\text { "Sometimes people don’t play because they don't have any } \\
\text { friends.” } \\
\text { “[Children] try and hide from the bullies so they can’t do } \\
\text { much playing.” }\end{array}$ \\
\hline & - Peer barriers & $\begin{array}{l}\text { "You are very influenced by your friends...if they don’t } \\
\text { want to play then you won’t be influenced [to play].” }\end{array}$ \\
\hline Teacher Influence & - Teacher barriers & $\begin{array}{l}\text { "All the fun stuff, the teachers say "that's dangerous. } \\
\text { You're not allowed to do that"., }\end{array}$ \\
\hline
\end{tabular}


The most important perceived facilitators of lunchtime physical activity

\begin{tabular}{|c|c|c|}
\hline Factors & Sub-factors & Quotes \\
\hline \multicolumn{3}{|c|}{ Physical environment } \\
\hline $\begin{array}{l}\text { Suitability of } \\
\text { space }\end{array}$ & $\begin{array}{l}\text { - Suitability of space } \\
\text { for a chosen } \\
\text { activity }\end{array}$ & $\begin{array}{l}\text { "Footy on the tennis court or on the gravel is heaps hard...so } \\
\text { I play on the oval." }\end{array}$ \\
\hline $\begin{array}{l}\text { Access to } \\
\text { equipment }\end{array}$ & & $\begin{array}{l}\text { "All the sports equipment you can get from the sports shed, } \\
\text { like hula hoops, balls, almost anything." }\end{array}$ \\
\hline Weather & - Types of weather & $\begin{array}{l}\text { "You can do [skipping] in any weather... and when you do } \\
\text { skipping when it’s cold it warms you up." }\end{array}$ \\
\hline \multicolumn{3}{|l|}{ Intrapersonal } \\
\hline Enjoyment & - Socialising & $\begin{array}{l}\text { “The game is also good because...you can’t find a good } \\
\text { hiding spot which sort of makes the game more interesting.” } \\
\text { "It’s fun because my friends are there and it’s really fun } \\
\text { being with them and doing something that I enjoy.” }\end{array}$ \\
\hline Self-efficacy & $\begin{array}{l}\text { - Perceived } \\
\text { competence }\end{array}$ & "I am really good at handball so I play all the time." \\
\hline $\begin{array}{l}\text { Behavioural } \\
\text { attitude }\end{array}$ & $\begin{array}{l}\text { - Practice to get } \\
\text { better } \\
\text { - Socialisation } \\
\text { - Something to do }\end{array}$ & $\begin{array}{l}\text { "We both play in the school cricket team so we treat } \\
\text { lunchtimes and recess times as practice mainly." } \\
\text { "Playing football is a form of hanging out with friends." } \\
\text { "I guess it's just something to do rather than just sitting } \\
\text { down.” }\end{array}$ \\
\hline $\begin{array}{l}\text { Belief about } \\
\text { physical activity }\end{array}$ & $\begin{array}{l}\text { - Make up your own } \\
\text { rules }\end{array}$ & $\begin{array}{l}\text { “At recess and lunch you don’t have to play by the rules so } \\
\text { much. You can make up your own rules. You can make it } \\
\text { much funner than normal games.” }\end{array}$ \\
\hline $\begin{array}{l}\text { Feelings about } \\
\text { physical activity }\end{array}$ & - Activity preference & $\begin{array}{l}\text { "I prefer handball and pokemon because I like it, it's the two } \\
\text { best things." }\end{array}$ \\
\hline \multicolumn{3}{|c|}{ Social environment } \\
\hline Peer Influence & $\begin{array}{l}\text { - Someone/friends to } \\
\text { play with }\end{array}$ & $\begin{array}{l}\text { "All they do is walking and they're probably not going } \\
\text { anywhere. They might just walk around in circles and stay in } \\
\text { one place but if you have a couple of friends you might play }\end{array}$ \\
\hline
\end{tabular}


chasey."

- Peer acceptance “The people think you are uncool if you are not doing it [skipping].”

- Peer support "I want to play with the boys and my friends say ok so then I just do it.”

Teacher influence • Teacher support “[Teachers] give us better ideas about what to do and stuff.” 